\title{
Diversity of Function of SCN Pacemakers in Behavior and Ecology of Three Species of Sciurid Rodents
}

\author{
Patricia J. DeCoursey
}

Department of Biological Sciences, University of South Carolina, Columbia, U.S.A.

\begin{abstract}
Information on the widespread function of the suprachiasmatic (SCN) pacemaker has increased dramatically in the past decade for laboratory rodents and for humans. Interest is now also growing in the adaptive value of SCN pacemakers in wild species of free-living mammals in natural pristine habitat. The squirrel family, Sciuridae, is highly diverse in North America. Radiation into many specialized groups has evolved in response to the temporal and spatial characteristics of specific habitats. The sciurids thus offer possibilities for comparison of SCN function for closely related species from very different habitats. Results from field and laboratory investigations concerning the ecological significance of the SCN are reported here for three ground squirrel species. The semi-fossorial antelope squirrels of the American southwest deserts were arrhythmic in above ground activities after deletion of the SCN pacemaker. In a desert enclosure, predation rates rose dramatically for lesioned animals in comparison to intact controls. The semi-arborial chipmunks were prone to capture by mustelid burrow predators such as weasels after SCN-deletion, even though the chipmunks did not exhibit any above ground activity at night. The telltale cue for the predator was apparently arrhythmic restlessness within the complex home burrow. The semi-fossorial golden-mantled squirrels of the Cascade Mountains of western United States rely on profound, long-lasting hibernation for over-wintering. Periods of torpor alternate with brief euthermic arousal episodes lasting less than 24 $\mathrm{h}$ throughout the 5- to 8-month winter phase. Deletion of the SCN in golden-mantled squirrels resulted in aberrations of hibernation arousal patterns that were metabolically expensive and put individuals at risk of starvation immediately after emergence in spring.
\end{abstract}

Keywords: Circadian rhythm adaptiveness, SCN pacemaker, hibernation, predation, ground squirrels, chipmunks.

Address correspondence to: P.J. DeCoursey, Department of Biological Sciences, 700 Sumter Street, University of South Carolina, Columbia, SC 29208, U.S.A. Fax: (803) 777-4002; E-mail: dcoursey@biol.sc.edu.

DOI: $10.1080 / 09291010412331313214$ (C) 2004 Taylor \& Francis Ltd. 


\section{Introduction}

Interest in the ecological importance of circadian pacemakers has grown at an ever-increasing rate in recent years. Multiple circadian pacemakers have been demonstrated in mammals, but without a doubt the dominant and coordinating pacemaker is the suprachiasmatic nucleus $(\mathrm{SCN})$ of the ventral hypothalamus. (Moore \& Leak, 2001; Takahashi et al., 2001). Since the founding of the field of Chronobiology in the early 1950s, most research on mammalian species has concentrated on laboratory rodents and humans. Early work on laboratory mice helped define basic formal properties of circadian rhythms (Aschoff, 1964). Later research delineated the structure and physiology of the SCN system, primarily in mice, rats, hamsters, and humans (extensive reviews in Aschoff, 1981; Klein et al., 1991; Takahashi et al., 2001; DeCoursey, 2003a, b, c). Advances in the molecular genetics field allowed isolation of the Clock gene of laboratory mice and the eventual cloning of a mammalian clock gene for the first time (Vitaterna et al., 1994). All of these approaches have reinforced the idea that the SCN is found in most mammals and that the pacemaker is important in mammalian physiological and behavioral functions.

In spite of the widespread conviction about the significance of the SCN for temporal regulation in mammals, little concrete evidence has accumulated about its precise role in wild mammalian species under natural field conditions (Alleva et al., 1995; DeCoursey, 2001). The reasons for emphasis on laboratory rodents and humans are obvious: availability, genetic uniformity, and ease of maintenance. The negative side of domesticated rodents in stereotyped laboratory conditions is the lack of information about survival and functioning of free-living, wild species competing in their natural habitat niches. Progress in accumulating information in the wild has been slow because of the daunting challenges (DeCoursey et al., 2000). Subjects must be located in pristine, preferably wilderness areas free of human interference, permanently marked, brought into the laboratory for the SCN-lesioning, then repatriated at their home dens within a few days. Subsequently, parameters of longevity, mortality, and daily activity rhythms, as well as specific physiological features must be tracked continuously for the subjects' remaining lifetimes. Automated telemetry such as radio tracking and implanted data loggers or transponders has eased the burden of these tasks, but the expense and energy demands for the tracker are still a major deterrent to data acquisition (DeCoursey et al., 1997).

The earliest available data for the functions of mammalian SCN pacemakers under field conditions dealt with simple mortality (DeCoursey et al., 1998). More recently new insights have been gained into behavioral features relative to predation and hibernation of several sciurid rodents (DeCoursey, 2001). The squirrel family (Sciuridae) is highly varied in its basic ecology and therefore provides an ideal opportunity for a comparative study. All species are diurnal except for the nocturnal flying squirrels. Habitat forest niches occupied by members of the squirrel family include a simple arboreal condition in gray squirrels (genus Sciurus) or red squirrels (Tamiascurus), aerial gliding between trees in the flying squirrels (Glaucomys), or a semi-terrestrial life-style in the chipmunks (Tamias). In addition, a group of approximately 60 ground- 
squirrel species, particularly in western United States, are semi-fossorial. These species include the true ground squirrels (Spermophilus), the desert antelope ground squirrels (Ammospermophilus), prairie dogs (Cynomys), and social fossorial ground squirrels of high elevation mountains or northern latitudes (Marmota). All ground squirrels are day-active and spend a large part of the day on the substrate surface but invariably retreat to a sheltered burrow during nighttime darkness. Paralleling the diversity of niches occupied by these different species are temporal differences in regulation of daily and annual behavioral and physiological functions by the SCN pacemaker.

A summary of recent information about the importance of the SCN in the temporal ecology of three ground squirrel species follows below. The eastern chipmunk of the Allegheny Mountains of Virginia, the white-tailed antelope squirrel of the Mojave Desert of California, and the golden-mantled squirrel of central Oregon were chosen as subjects since they present a cross-section of life-styles in the squirrel family.

\section{Material and Methods}

\section{Study sites}

Laboratory recording of circadian rhythms and hibernation rhythms were carried out for the three species primarily at the University of South Carolina, Columbia, SC. A Hibernaculum capable of housing 23 golden-mantled squirrels was also established at the University of South Carolina.

The field research with antelope ground squirrels (Ammospermophilus leucurus) took place at the Desert Research Station of Barstow County School District, near Hinckley, California. A 1-m high enclosure built of cinder block was constructed on natural Mojave Desert substrate. Artificial underground burrows were installed to accommodate each individual. After the unexpected loss of many project animals in a single night from predation by a feral cat, a wire mesh roof was added. The methods for monitoring circadian activity in the enclosure included visual recording from an enclosed observation cubicle adjacent to the enclosure, infrared videotaping, transponder recording, and heat-sensor recording.

The field project with chipmunks (Tamias striatus) was conducted near Blacksburg, Virginia on five hectares of pristine oak forest at the University of Virginia's Mountain Lake Field Station. Census trapping stations were established in a grid pattern throughout the study site. In addition, a small Hibernaculum for holding 5 chipmunks over winter under natural conditions was constructed in a well shaft adjacent to the study grid.

The fieldwork with golden-mantled squirrels (Spermophilus lateralis) entailed an 11-year project involving four sites. The definitive site was located on approximately 20 hectares of mature high-desert Ponderosa Pine forest in the Metolius Research Natural Area of Deschutes National Forest, on the east slope of the Cascade Mountain Range of central Oregon. A live-trapping grid was set up for censusing and capturing project animals. 


\section{Animals and care}

The three species were collected from the field with National live traps. The antelope ground squirrels were first brought back to the University of South Carolina for several years of behavioral research on their circadian locomotor activity rhythms. Subsequently SCN surgeries were carried out for one group, and all animals were transported back to the site of capture at the Desert Research Station for installation in the enclosure. The chipmunks were trapped from the study site, brought for approximately one week into the laboratory for recording of locomotor activity before and after SCN surgery, and then repatriated at their home burrow. The golden-mantled squirrels for the field project were trapped from the central core area of the Metolius study site. They were brought into a small laboratory at nearby Wizard Falls Fish Hatchery for SCN surgery and for installation of the iButton data loggers. After a recovery period of four-five days they were repatriated to their sites of capture.

During laboratory holding, all species were fed a staple diet of sunflower seed and lab chow biscuits, with occasional fresh food supplements. The work was conducted under Protocol permits approved by the Animal Resources Department of the University of South Carolina, Columbia, SC.

\section{Surgical and recoding methods}

Surgery for SCN deletion involved stereotaxic electrolytic procedures. Brain maps were constructed from histological serial sections of lesioned animals for all three species. The skull suture landmark bregma was used for chipmunks. Since the other two species lacked skull sutures as adults, the mid-line crossing of a line drawn between the posterior edges of the right and left zygomatic processes served as the reference landmark. After mounting anesthetized animals in a Kopf stereotaxic apparatus, bilateral lesions were made with custom-built platinum-iridium electrodes from FHC, Inc. The electrode was lowered to the desired coordinate position and a current of $2.5 \mathrm{mAmps}$ delivered for $20 \mathrm{~s}$. The animals were awake in about one hour, and within a day they behaved normally except for arrhythmicity of locomotor activity.

At the completion of experiments, histology was carried out for the hypothalamic region of all SCN-lesioned antelope ground squirrels and golden-mantled squirrels in order to determine lesion success. Since the chipmunk work was conducted on a protected reserve area that did not permit removal of individuals from the population, activity recording served to diagnose completeness of lesions; in addition, calibration chipmunks from other nearby areas were SCN-lesioned and brain histology checked to estimate lesion success.

Wax-coated Thermochron iButtons were implanted intraperitonally in goldenmantled squirrels for long-term recording of body temperature during hibernation. For the other two species, radio transmitters (ATS, Inc.) were attached to neck collars and tied snugly around the neck of each project animal. Collar signals could be tracked manually with a hand-held Yagi antenna or continuously with a pole-mounted antennae and a data logger (ATS, Inc.). 


\section{Data analysis}

Wheel-cage data were collected on Esterline-Angus recorders. The resultant traces were processed into 24-h actographs for examining the presence of free-running rhythms or arrhythmicity, as well as entrainment to an LD light cycle. Radio tracking was used in summer primarily for location and mortality determinations. In winter, chipmunks wore temperature-sensing collars, which documented topor periods and also mortality. The Thermochron iButtons were implanted in goldenmantled squirrels in late summer. They were retrieved and downloaded in May after the termination of hibernation. The iButton data provided a continuous record of body temperature at 3 -h intervals for 8 months.

\section{Data}

\section{Circadian locomotor activity regulation based on an SCN pacemaker}

The SCN nucleus in its location and structure is very similar in all three species studied. The paired lobes are located directly above the optic chiasm separated by the third ventricle of the brain (Fig. 1A). The small, densely packed neurons are strongly Nissl positive in their staining properties; the presence or absence of intact ependymal cells lining the third ventral is also a helpful diagnostic feature. Lesions targeted the bilateral nuclei while sparing the optic chiasm. In some cases a small triangular hole above the optic chiasm and the lack of the ependymal cells was the mark of a complete lesion (Fig. 1B). In other cases the third ventricle was lacking as well as the SCN neurons and the space was filled with cell debris.

In all three species, the generation of daily activity rhythmicity was regulated predominantly if not exclusively by an SCN pacemaker. In dim light or continuous darkness, wheel-running rhythms of intact animals deviated in a regular, predictable circadian fashion from $24 \mathrm{~h}$ (Fig. 2A-C). Control animals entrained to a light-dark

A.

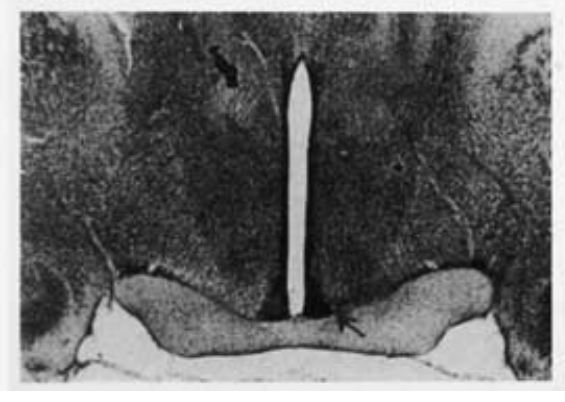

B.

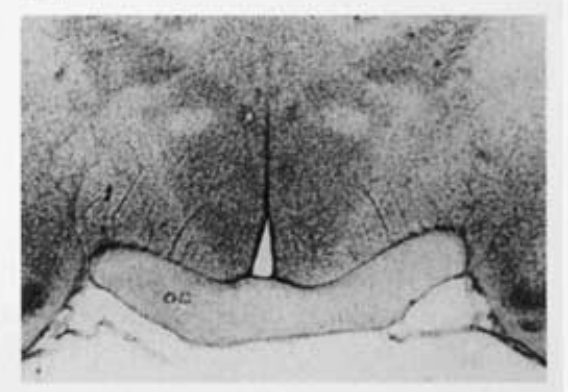

Figure 1. Coronal sections of the ventral hypothalamus of chipmunks: A. Intact control. B. Completely lesioned individual. Nissl stain, $80 \mathrm{u}$ sections. Arrow in A points to SCN, oc $=$ optic chiasm. (From DeCoursey, 2001). 

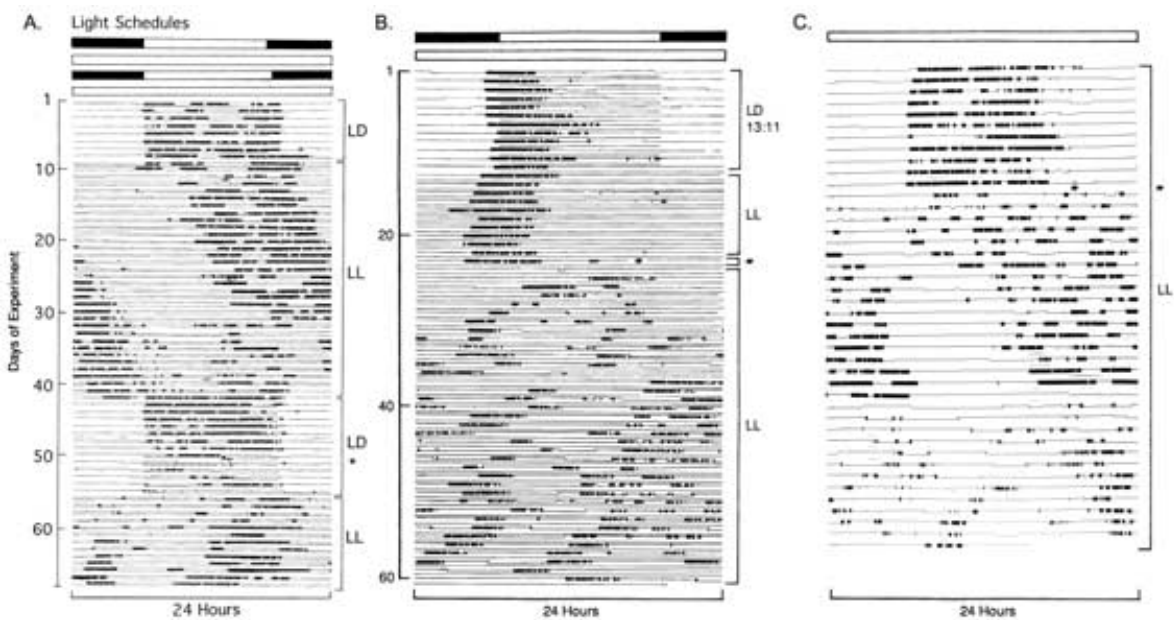

Figure 2. Single-plot actograph of wheel-running activity under lighting conditions indicated by light bars above; faint underlining in $\mathrm{A}$ and $\mathrm{B}$ also indicates light on. An asterisk in each actograph indicates the time of SCN lesioning. A. Antelope squirrel, B. chipmunk, and C. Golden-mantled squirrel. For further explanation see text. (Adapted from: A DeCoursey et al., 1997; B. DeCoursey et al., 1998; and DeCoursey, unpublished).

schedule such as LD 12:12 with a major block of wheel running in the light period, rest time chiefly in darkness, and a period very close to $24 \mathrm{~h}$ (Fig. 2A-B). Partially lesioned animals showed varying degree of disruption of the regularity of the locomotor rhythms, with the amount of change dependent for the most part on the proportion of SCN tissue remaining. In cases of complete SCNlesioning, the running-wheel activity was arrhythmic in constant conditions (Fig. 2A-C).

\section{Other effects of SCN lesions}

No attempt was made to document exhaustively all possible effects of SCN lesioning on the physiology, behavior, and general ecology of the three species. Instead, the challenges of terrain, life history, and habits of the species dictated which parameters were feasible ones to measure in each species.

\section{Antelope ground squirrels}

The first species examined was the antelope ground squirrel. Background information about its social and activity rhythms under field and laboratory conditions existed in the published literature (Karasov, 1981; Zucker et al., 1983). Antelope squirrels do not hibernate and are therefore available for study throughout most of the year, although they remain relatively inactive in their burrows during most of the winter months from November through February. The Mojave Desert ecosystem inhabited 
by antelope ground squirrels is very sparsely covered with xeric vegetation. Individuals leave their burrows frequently for extensive feeding forays above ground. As a consequence, the visibility of animals both in the enclosure and on the open desert makes them suitable for observation during daytime and at night. Published data confirm the strongly diurnal nature of surface activity of totally wild individual throughout the day (Karasov, 1981; DeCoursey et al., 1997), and a restriction of intact control individuals to their enclosure burrows during hours of darkness (DeCoursey et al., 1997).

The extensive trips above ground cause difficulties in radio tracking and radio logging since the range of the tracking and data logging equipment is at most several hundred meters. The strongly social habits of antelope ground squirrels made it possible to place up to 10 individuals in the enclosure without harmful territorial interactions. In view of the constraints of the habitat and far-ranging surface foraging of antelope squirrels, the emphasis of the circadian field project for this species was an enclosure protocol.

Videotaping showed that a feral cat was preying on some of the animals during the first night of operation of the enclosure. The cat leaped over the compound wall after dark and waited motionless until an individual squirrel left its burrow. Starlight and moonlight reflecting off the white desert sand made activities such as sand bathing or foraging for food relatively easy for the ground squirrels at night. Apparently the squirrels were totally unaware of the waiting predator. The result was always the same: a pounce by the waiting cat, a bite on the neck, and the death of the antelope squirrel. The cat immediately carried the dangling body out of the enclosure, perhaps to feed a nearby litter, and soon returned to wait for another victim to emerge. The procedure continued until the first lightening of the sky at dawn. The enclosure was immediately decked with protective wire covering.

The number of SCN-lesioned animals captured by the cat was significantly higher than for intact control, non-lesioned squirrels. Sixty percent of the lesioned squirrels that came above ground during the first night were killed by the cat, while only $29 \%$ of the intact ones surfaced from their protective burrows onto the sand substrate and were swiftly captured (Fig. 3). The composite data revealed the probable reason; videotaping, transponder records of feeding at the food canister, locomotor activity recording, and direct visual observations showed different aspects of the chain of predation events. Wheel turning data had indicated that intact controls restricted activity above ground to daylight hours while SCN-lesioned animals were active in small blocks of time during both subjective day and night (Fig. 2A). In the enclosure, transponder data documented that intact individuals were active above ground chiefly during the day and occasionally in the predawn twilight (Fig. 4A). In contrast, the SCN-lesioned squirrels frequently came above ground at night for extended periods of time. They scampered on the sand, dust bathed in the sand, and fed at the food canister (Fig. 4B). The antelope squirrel results portrayed the protective function of activity regulation by the SCN pacemaker: a retreat to a deep burrow during nighttime and restriction of above ground activity to the hours of daylight. 


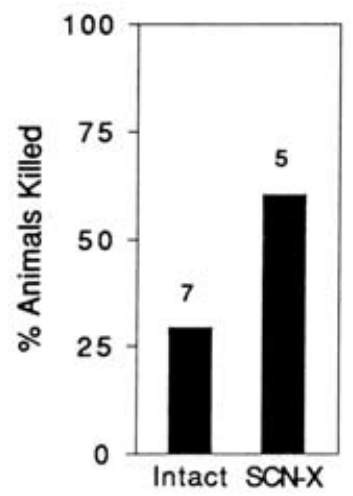

Figure 3. Relationship of nocturnal activity and predation in five SCN-lesioned and seven intact antelope squirrels. (Adapted from DeCoursey et al., 1997).
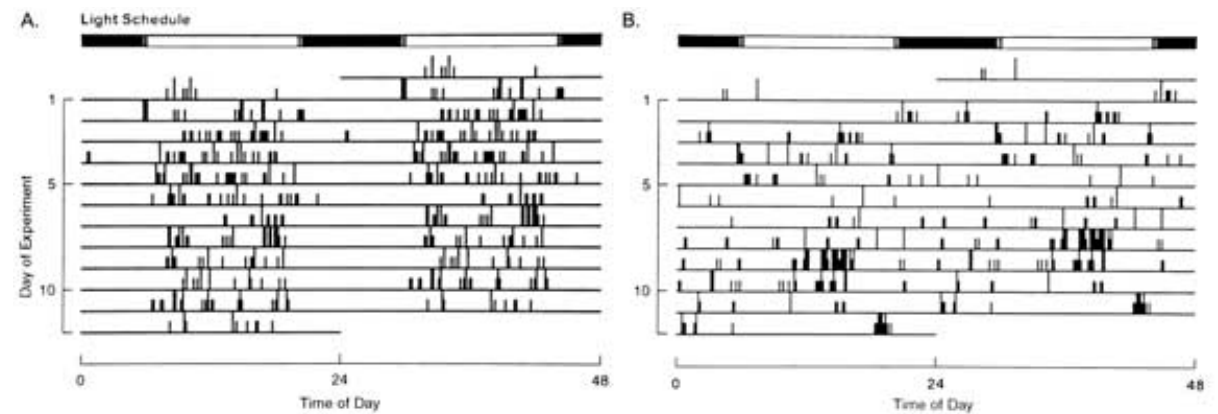

Figure 4. Double-plotted transponder data for surface activity of antelope ground squirrels in an enclosure for 12 days, summed for each protocol group. Vertical lines are bouts of activity per $10 \mathrm{~min}$. Light conditions shown by light bars above. A. Intact animals, B. SCN-X animals. (Adapted from DeCoursey et al., 1997).

\section{Eastern chipmunks}

The chipmunk studies extended survival studies to a large number of wild-caught SCN-lesioned individuals and intact controls in natural habitat. Daily radio tracking facilitated monitoring individuals for extended periods of time during a four-year study. Background information on the life history strategy of chipmunks has been extensively published (Wrazen \& Wrazen, 1982; Wolff, 1996; DeCoursey et al., 1998, 2000). Even though antelope squirrels and chipmunks are both semi-fossorial and almost identical in size, they differ widely in their ecology and meet very different constraints on their daily and seasonal behavior. The chipmunk project took place in densely forested mountainous terrain of the Allegheny Mountains of western Virginia. Hardwood hickory and oak trees form the canopy cover. The ground substrate is densely covered with herbaceous plants. Abundant rainfall favors very thick stands 
of plants such as cinnamon and interrupted ferns that reach a height of approximately $2 \mathrm{~m}$. In such habitat practically no nighttime light reaches the substrate during summer. As a result, the den entrance and the small territory of each chipmunk are almost totally dark at night.

Under these conditions, the summer behavioral cycle of the chipmunks involved above ground activity of adults during warm sunny days from shortly after dawn to a few hours before sunset (Fig. 5). Apparently the chipmunks are functionally blind at night. Repeated checks for nighttime activity by several methods never detected a single chipmunk outside its burrow at night. As fall approached, daytime activity was directed predominantly towards acorn collection and storage. Each individual carried acorns stuffed into its cheek pouches to a sunny spot for drying, and then stockpiled the harvest in special pantry chambers adjacent to its leaf-lined nest chamber. Chipmunks store almost no winter body fat as a winter energy supply. In some cases torpor accompanied by a slight lowering of body temperature occurred during extended periods of intense cold if food was scarce. True hibernation is not possible, however, since a body temperature lower than $15^{\circ} \mathrm{C}$ is lethal. The relative inactivity during winter months helps conserve the food cache. As spring approached in late March and April, the males could often be seen, even when the ground was deeply covered with snow, sitting high on a display rock presumably waiting for females to appear for mating.

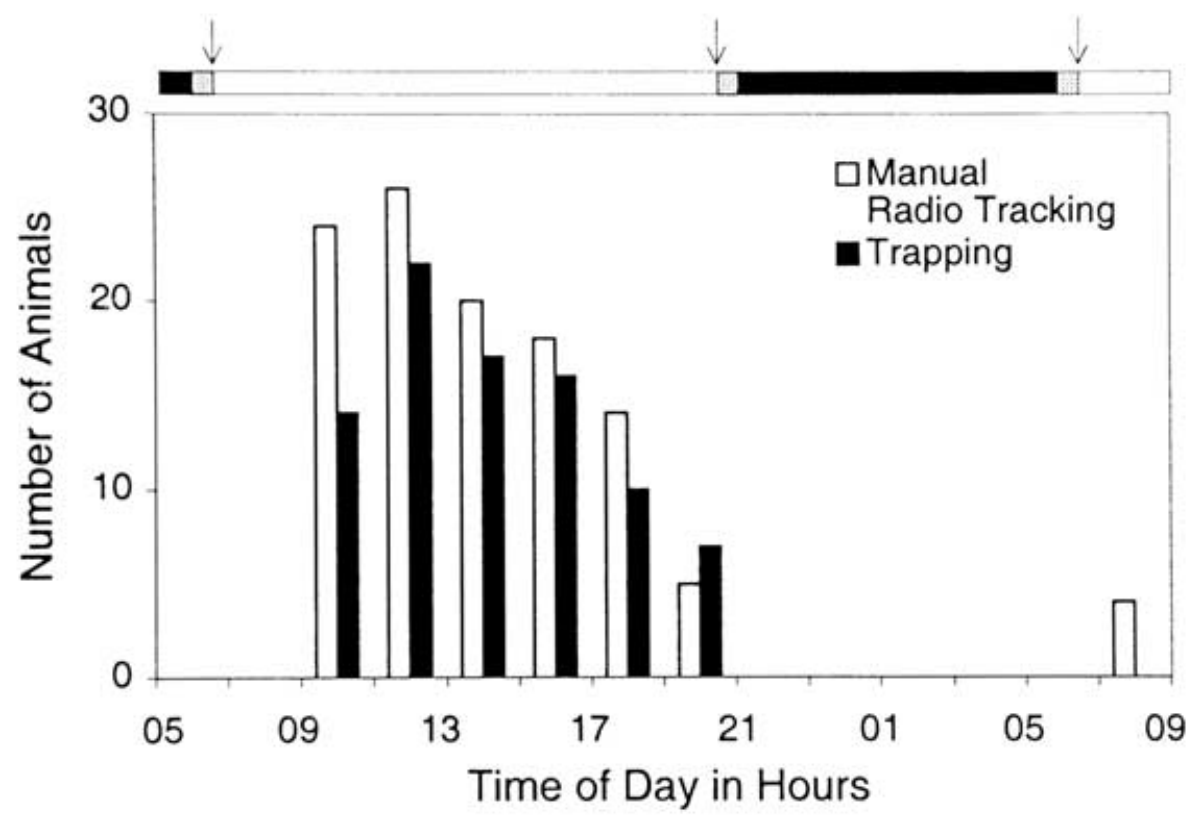

Figure 5. A 28-h continuous census at 2-h intervals of chipmunk activity above ground in mid-summer by two methods, manual radio tracking and live trapping. Light conditions shown by light bar with arrows for sunrise and sunset. (Adapted from DeCoursey et al., 1998). 
Chipmunk population levels fluctuate markedly in a 4-5-year periodicity that is correlated with the size of the acorn crop (Bowers 1995; Wolff, 1996; DeCoursey et al., 2000). Population density of chipmunks at the study site built up after 2 successive favorable acorn crops from as few as one or two individuals per hectare to about 25 per hectare. Radio-telemetry data and direct visual observations showed that in years of low population density, little mortality of chipmunks was detected. In one low-density year, the only mortality during an entire summer and autumn occurred when an intact displaying male failed to notice a large dog intruding into the study area. The chipmunk was given a lethal bite before being discarded. In a following 5month winter, several empty radio collars were retrieved from the forest floor or within a den. These suggested a small, highly mobile predator that was capable of penetrating the owner's burrow system. In contrast, the outcome was very different after build up of population density. The evidence for mortality in this case was compellingly in favor of weasel predation. In the final year before the crash of the very high-density population, approximately one chipmunk disappeared each night (Fig. 6). Retrieval of the collars by tracking led to chipmunk carcasses with weasel bites, animals killed and then buried within their own tunnels, as well as chipmunks partially eaten and then cached in diverse places for later consumption.

A significantly higher proportion of SCN-lesioned chipmunks died from weasel predation than intact or surgical controls. Data from multiple kinds of telemetric recording and extensive visual observation period gave new insights into the function of an SCN-pacemaker in the life strategy of eastern chipmunks (DeCoursey et al., 1998, 2000). Intact chipmunks both in the field and in running wheels in laboratory recordings displayed strictly day-active patterns of behavior. Recording of movement within the dens at night recorded by the automated radio telemetry data revealed a consolidated sleep period (Fig. 7A). In this procedure, the amplitude (gain) of the

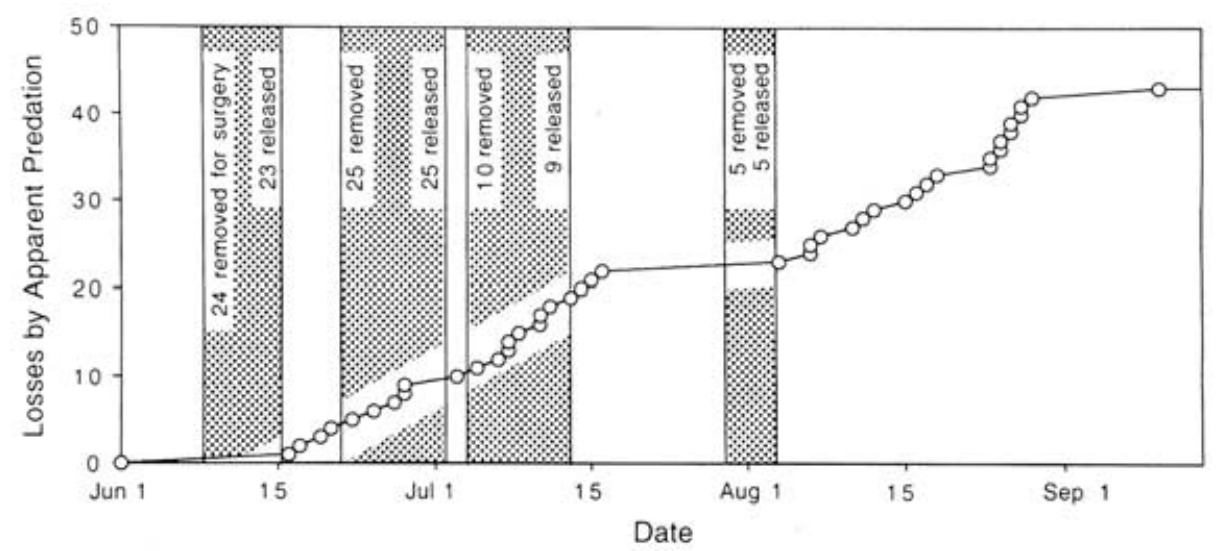

Figure 6. Mortality of radio collared chipmunks at the field study site as a daily cumulative record. Time spent in the laboratory for surgery and collar attachment is shown for four separate groups by the dotted blocks. (From DeCoursey et al., 2000). 

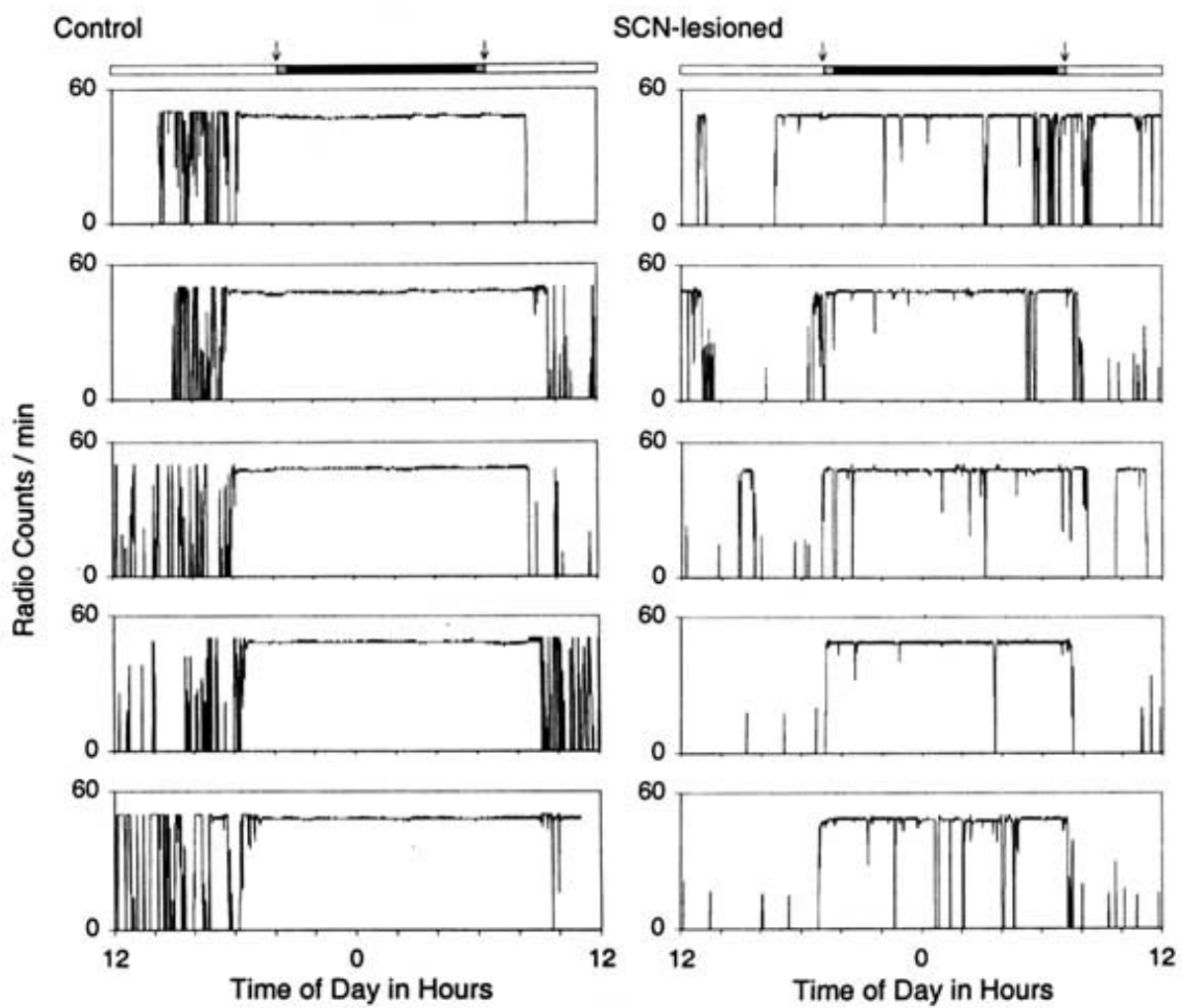

Figure 7. Actograph of chipmunk den activity movements over 5 consecutive 24-h periods from Day 1 on the top of each actograph stack to Day 5 at the bottom of each stack, monitored continuously by a radio collar, radio receiver, and data logger. The receiver sensitivity to incoming signals (the gain) has been reduced to respond maximally at 55 counts/min only when a chipmunk is motionless in its nest chamber directly below the Yagi receiving antenna. A. Intact control, and B. SCN-X. Above ground lighting is shown by light bars. (From DeCoursey et al., 2000).

receiver is reduced until the Yagi antenna picks up radio collar signals only from the small area directly above a chipmunk's single nest chamber, but not from the remainder of its extensive burrow system. When the chipmunk moved at least $0.5 \mathrm{~m}$ down its long burrow, the radio counts dropped from about 55 "beeps"/min to zero. The continuous count level of 55 beeps/min for intact controls at night indicated a motionless position. Loss of the signal during daytime (radio count at 0 ) for this animal depicted excursions away from its den (Fig. 7A). In contrast, nighttime movements of an SCN-lesioned chipmunk less than $0.5 \mathrm{~m}$ in distance in its burrow, possibly due to restlessness, caused a drop in the beep rate proportional to distance and body position (Fig. 7B). SCN-lesioned animals both in the laboratory and in natural field dens showed a highly fragmented arrhythmic sleep/wake pattern. The restless episodes of 
SCN-lesioned chipmunks in their dens during nighttime suggested that one function of an SCN pacemaker is to keep an animal inactive while it is sequestered and sleeping in its den at night.

\section{Golden-mantled squirrels}

Still another life-style scenario is seen in the ground squirrels of the semi-desert east slopes of the Rocky Mountains and Cascade Range of western United States (Trombulak, 1987). The golden-mantled squirrel is a favorable species for study because of its solitary habits but high density in good habitat. It prefers open Ponderosa pine forests with low forest undergrowth, and this choice facilitates visual observations of the squirrels. Furthermore, the species exhibits profound deep hibernation for as much as eight months of the year and hibernation shows many interesting circadian features. Laboratory studies of its annual cycle and hibernation performance provide background for field studies (Dark et al., 1990; Milsom et al., 1993; Zucker et al., 1983; Grahn et al., 1994; Ruby 2003; Ruby et al., 1996, 1998; Pulawa \& Florant, 2000; Zimmer \& Milsom, 2001).

The 20-hectare study site was located in the Metolius Research Natural Area of the Deschutes National Forest in central Oregon in a mature undisturbed Ponderosa pine forest. Five-year prescribed burns favored lush growth of succulent herbaceous plants on the forest floor as well as subsurface growth of Oregon truffles. These fungi appeared to be the main summer food and water source in the high desert forest that lacks open running water. The population within the study site reached about 300 individuals each year after emergence of young from their burrows in June. Density dwindled to approximately 80 individuals by the following spring emergence due to predation and winter starvation.

Life history strategy was gender and age dependent (DeCoursey, 2003b). Adult males were euthermic by late February and active above ground by midMarch. Mating took place at the end of May or in early June. Males then rapidly built up body fat and become scarce above ground as soon as intense drought began, usually in late July or early August. Under favorable weather conditions, males could be seen active above ground until fall; they entered hibernation any time from early September up to November in warm, moist years. Females aroused from hibernation in mid-May, mated immediately, bore young in mid- to late June, and nursed the young for about one month. They were usually hibernating by late October. The juveniles were found above ground the longest, presumably in order to reach a critical body mass that could tide them through winter hibernation until mid-May.

Multiple methods of telemetric recording allowed delineation of the daily circadian cycle and the seasonal hibernation pattern. Studies were completed both at the Metolius field site and in a laboratory Hibernaculum that simulated field conditions of ambient ground temperature and lighting. Because of the many possible sources of mortality throughout the year, no systematic attempt was made to document causes of mortality. Rather, the role of the SCN pacemaker in the annual hibernation cycle was emphasized in the work. 
The control squirrels, both in the field and in the Hibernaculum, entered hibernation abruptly from a euthermic state, and similarly aroused from hibernation into summer euthermia directly from a deep torpor bout. The intervening period was divided into periods of hibernation torpid bouts interspersed with regular, approximately 24-h arousal episodes of euthermia (Fig. 8A). The obvious features of hibernation pattern included number of days of hibernation, start and end of hibernation relative to time of year, number of bouts, duration of bouts, and the presence of regular modulation of the length of bouts relative to time in the hibernation season. A direct relationship was seen between the lowering of ground temperature and the increase in length of a hibernation bout; the time in euthermia during arousal episodes also decreased proportional to ambient temperature.

During the study, no fully SCN-lesioned squirrels were recovered in the field in spring, although a few females with partial lesions containing as low as $10 \% \mathrm{SCN}$ were trapped in May. In contrast, 100\% of controls and SCN-lesioned animals survived in the laboratory Hibernaculum if normal feeding was reinstated as soon as individuals aroused from hibernation (Fig. 9). For this reason, conclusions about hibernation of SCN-lesioned squirrels must be based on Hibernaculum individuals. These squirrels were generally quite similar to the control animals. Most hibernated for an extended period, with bouts of approximately the same mean duration as controls. Closer examination, however, revealed a subtle difference in the degree of regularity of hibernation bouts for controls and SCN-lesioned squirrels. Aberrations in pattern of the SCN-lesioned animals included initial bouts with shorter periods, periods of euthermia during the envelope of hibernation lasting for several days, and irregularity in the modulation of torpor duration through the winter (Fig. 8B).

In one single exceptional case, no hibernation bouts occurred and the individual remained euthermic in its Hibernaculum cage for the entire winter. When the body
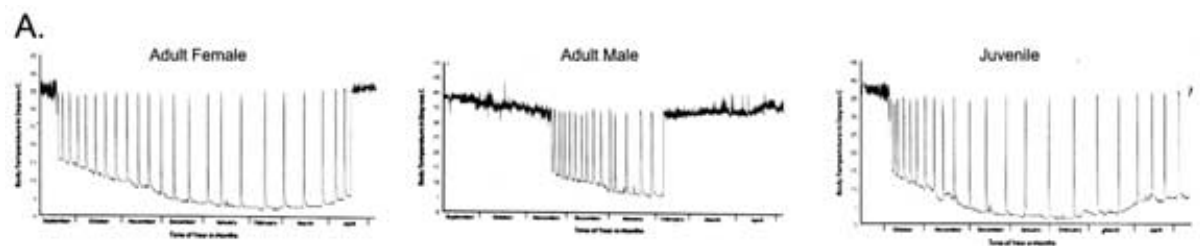

B.
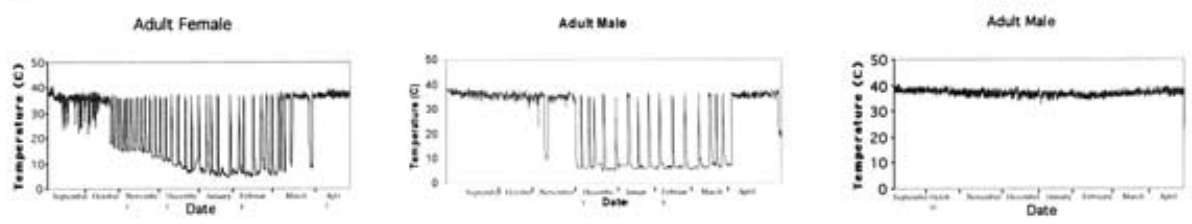

Figure 8. Body temperature patterns in hibernating golden-mantled squirrels recorded by implanted iButtons from September to May. A. Body temperature patterns for normal intact individuals during hibernation. B. Body temperature for SCN-lesioned squirrels during hibernation. (DeCoursey, unpublished). 


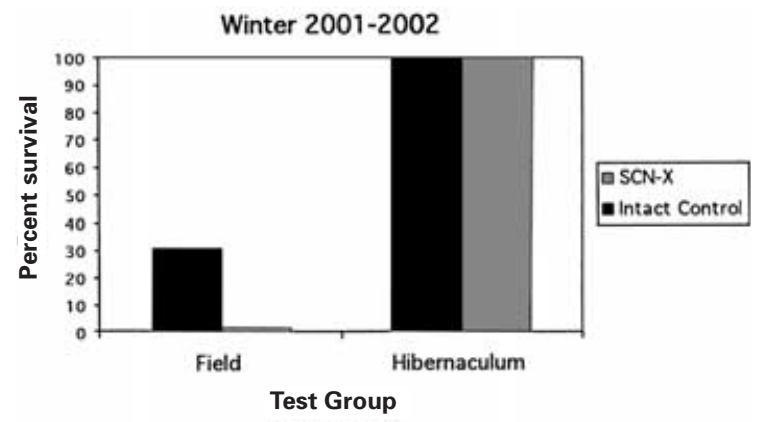

Figure 9. Survival of Intact and SCN-X squirrels in the field (left) and Hibernaculum (right) for winter 2001-2002. For further explanation see text. (DeCoursey, unpublished).

weight of this large male fell precipitously by mid-December to half his September level, low level supplementary feeding was instated to prevent death by starvation.

Several observations suggested that all golden-mantled squirrels both in the field and in the laboratory are at risk of starvation at the time of termination of hibernation. In the field situation $0 \%$ of lesioned animals were recovered in spring. In contrast, $100 \%$ of both intact and lesioned squirrels survived the winter in the Hibernaculum if food was supplied on a regular basis as soon as an individual aroused from hibernation (Fig. 9).

\section{Discussion}

\section{Multiple functions of the SCN in regulation of mammalian rhythmicity}

The SCN pacemaker of most small rodent mammals consists of two non-encapsulated segments that are seated one on either side of the third ventricle of the hypothalamus in slight depressions on the dorsal surface of the optic chiasm (Fig. 1A). The neurons are very small in size, relatively non-specialized, and few in numbers. Approximately 10,000-12,000 neurons are found in a rat SCN (Moore \& Leak, 2001). Surprisingly, the small suprachiasmatic nucleus affects practically every part of the animal.

Circadian regulation by the $\mathrm{SCN}$ is by means of a large array of both neural and endocrine messages (Fig. 10). Two general areas of the SCN are recognizable: the ventromedial core and the outer shell. Most of the primary neural connections of the SCN are intrinsic within the nucleus itself, and the extrinsic connections are generally close to the SCN. An example of an important primary relay station is the subparaventricular area, which lies directly above the SCN and extends backwards as the retrochiasmatic area. The densest extrinsic neural projection fibers occur in these two small areas. Also important as primary relays close to the SCN are the paraventricular nucleus and the intergeniculate leaflet of the hypothalamus. Secondary relays project in radiating rings outward to widely spaced centers in the brain and spinal column. Similarly, endocrine messages spread out to all parts of the organism. One 


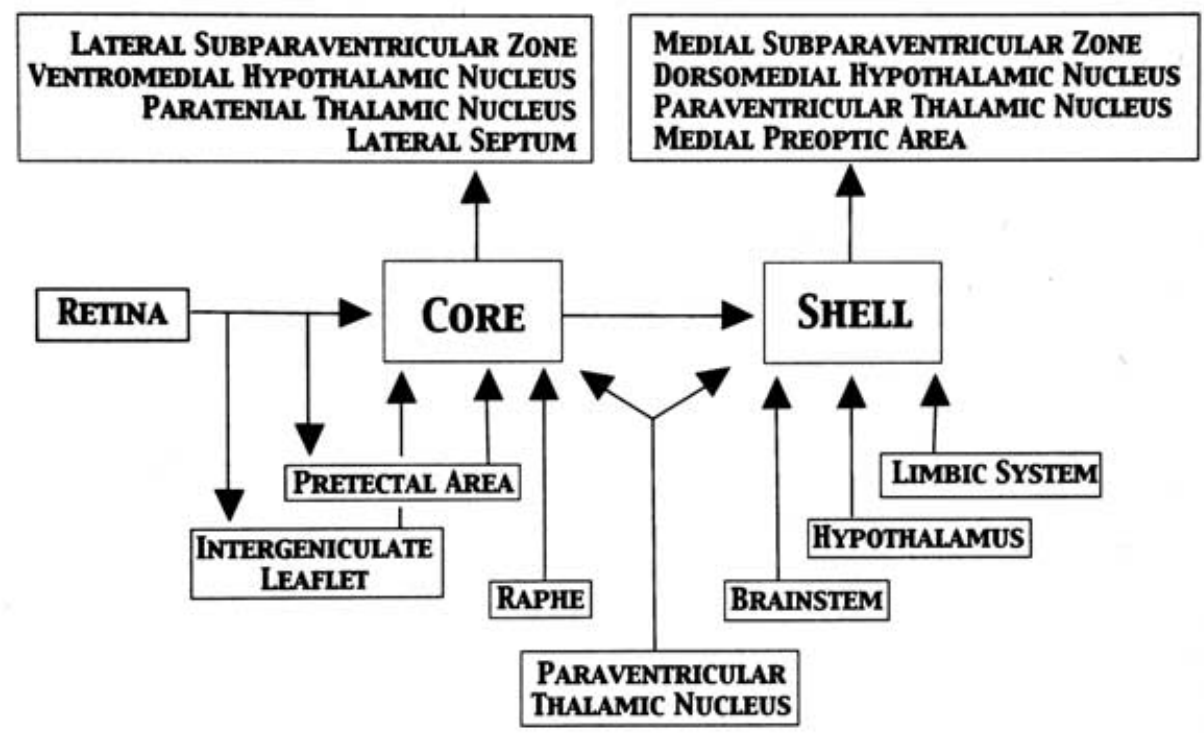

Figure 10. Schematic representation of inputs and regulatory outputs of the core and shell subdivisions of the SCN. (From Moore \& Leak, 2001).

important connection, for example, is a direct projection of the SCN to the pituitary gland. This master endocrine regulatory center is located just posterior to the SCN in the ventral hypothalamus. Another vital endocrine relay is the daily release of melatonin through the action of the SCN on the pineal gland. These neural and humoral connections eventually reach out to the most distant parts of the organism's body. In addition, several feedback loop connections bring back information to the SCN and help integrate its regulatory functions. The multiple representations of the circadian signal of the SCN are carried in various ways dependent upon the particular function of a target and its location.

In these ways the circadian signal generated in a small number of so-called clock cells is able to influence a large array of highly important biochemical, physiological, and behavioral rhythms in a mammal. A few glimpses of the complexity of circadian regulation by the SCN will give an overview of its tasks. In some instances the SCN acts as an alarm clock to awaken an organism in advance of need. Examples include the wake-up function of the sleep/wake cycles. Similarly, the clock may signal start time for daily locomotion or vocalization. Other behavioral cycles illustrating the start up function include activity level and efficiency. Physiological functions demonstrating circadian rhythmicity are very extensive, including endocrine levels, blood cell counts, and body temperature rhythms. Another task of the SCN is to serve as a chronometer to state the passage of time throughout the day for animals that use a constantly moving navigational compass such as the sun. Similarly, the chronometer is vital in photoperiodic mammals for measuring day length. Circadian 
neurohumoral connections are also important in estrous timing of female mammals. Still another function is the integrative task of coordinating the many daily rhythmic processes in correct phase with each other.

\section{Hibernation pattern of arousal episodes in sciurids}

The most common pattern of annual body temperature variation for sciurid species from high elevation sites above about $1,500 \mathrm{~m}$ in temperate latitudes or from northern latitudes is a profound, long-lasting winter hibernation and summer euthermia (Lyman et al., 1982; Zucker et al., 1993; Körtner \& Geiser, 2000). In winter, deep torpor bouts last for periods ranging from several days to several weeks. The torpor bouts alternate with brief arousal episodes of euthermia that last for less than $24 \mathrm{~h}$. Such a pattern is seen in sciurids such as Arctic ground squirrels (Barnes, 1989), golden mantled-squirrels (Dark et al., 1990; Zimmer \& Milsom, 2001), Richardson's ground squirrel (Michener, 1992), and European ground squirrels (Strijkstra, 1999; Strijkstra et al., 1999; Hut et al., 2002). Some cricetid rodents including the European hamster also have a similar winter pattern (Wollnick \& Schmidt, 1995; Wassmer \& Wollnik, 1997). Probably other deep hibernators from cold climates, such as the jumping mouse Zapus employ a similar strategy, but information on body temperature during hibernation is not available. The highly specialized phenomenon allows extreme energy conservation for extended cold winters when the ground remains frozen and minimal food is available either for storage in caches in fall or during winter.

In contrast, torpor is common on a daily basis in numerous desert species such as pocket mice, and kangaroo rats of the southwest deserts of the United States. The short-duration torpor of desert species may serve more as an energy-conserving device where food and water are scarce rather than as a long-term mechanism to escape subzero temperatures.

\section{Relationship of SCN function to the basic ecology of a wild species}

Life history patterns in small mammals have evolved in a history dependent fashion. Natural selection acts with respect to the species material available and the specific features of a particular niche. In Europe the single ground squirrel is the European ground squirrel (Spermophilus citellus). In contrast, North American ground squirrels include at least 4 genera, each with multiple species in all genera: the marmots (Marmota), true ground squirrels (Spermophilus), prairie dogs (Cynomys), and antelope ground squirrels (Ammospermophilus). More than 50 North American species of Spermophilus occur in western United States. Most of these arose in the past 25,000 years during the period of rapid tectonic upheaval that produced the great Rocky Mountain Range in western North America. Individual populations were cut off in separate valleys, and as a result speciation occurred rapidly. The honing of species by slightly differing climatic rigors placed different regulatory demands on the evolving SCN. The diversity of species functions in sciurid rodents is therefore not surprising. Examples are seen in the three species reported in this study. 
All three species from this study are diurnal and semi-fossorial. They spend the entire rest period and considerable parts of daytime in a burrow that extends $0.5 \mathrm{~m}$ to several meters underground. All three have almost exclusively cone vision with little capacity for vision at night. They are euthermic and active from spring to fall, and largely inactive during winter. Other similarities include their predominantly seedeating habits. Here the similarities cease, probably because the three species have evolved in strikingly different habitats. Antelope squirrels inhabit the open expanses of the southwest deserts where summers are intensely hot and winters mild enough for true hibernation to be unnecessary. Chipmunks are dense forest dwellers that are apparently behaviorally blind at night in the dense ground cover of the forest floor where most of their activity takes place. Populations are highly cyclic; the noncoinciding production years of the dominant three species of oak (white, red, and black oaks) peak every 4 to 5 years and provide plentiful acorns to fill chipmunk storage caches with winter food. The Eastern chipmunk at the Mountain Lake study site is not true a hibernator and neither stores body fat for winter energetic considerations nor enters deep hibernation. They merely lower their body temperature slightly during prolonged cold spells and pop above ground after several warm days to replenish their acorn hoard. Golden-mantled ground squirrels are denizens of the xeric high desert of the east slope of the Cascade Mountains of western United States. Summer aestivation and winter hibernation are profound and obligatory during the intense droughts of late autumn and the deep cold of a prolonged winter. Food is unobtainable during extreme autumn droughts or during winter when the forest substrate is frozen and covered with deep snow. A food supply for fall and winter must be stored as body fat.

The ecology of the three species studied gives insight into the results obtained in this study. The intact antelope ground squirrels in both field and enclosure were almost strictly day-active above ground, with only a few coming to the surface in the twilight predawn period. The SCN-lesioned animals expressed their arrhythmicity by coming repeatedly above ground to feed and to scamper and groom in the sand. Apparently the treeless terrain and the wide-open sky provided enough light from stars and moon to permit limited night activity but not enough light to detect a motionless waiting predator. Presumably the cat predator detected the squirrels originally by olfactory means, and then leaped the compound walls in darkness. It waited until a squirrel left its burrow and walked out onto the sand for activity at an inappropriate time of day. One important function of the SCN in wild species may be to keep an animal inactive at times of day for which it is not optimally adapted.

SCN-lesioned chipmunks were also arrhythmic in their natural habitat, but never left their burrow during the hours of darkness. Possibly too little light reached their burrow entrances and their pathways in the dense fern ground cover of the forest to provide vision, and the chipmunks were unwilling to venture out of their burrows. Little effect of lesioning was seen in years of moderate population levels, but in a high-density year predation was catastrophic. Chipmunk numbers on the study site plummeted from 100 to 4 individuals in a 4-month time span. The cause was almost exclusively a voracious weasel or group of weasels that could detect the restless move- 
ments of a lesioned chipmunk within its extensive burrow system. The data support the hypothesis that an important function of the SCN is to maintain the normal diurnal cycle of activity of an animal and inactivate movement during nighttime periods; the chipmunk is ostensibly safest if it is sleeping or curled up motionless at night in a nest chamber deep within its burrow system.

The ecological and physiological role of the SCN for intact control and SCNlesioned golden-mantled squirrels in natural habitat is not yet clear. Although predators are plentiful, the importance of predation in golden-mantled squirrel mortality is unknown. The rigors of the habitat did not make extended nighttime visual or radio tracking observations feasible. Under laboratory conditions, all SCN-lesioned animals were unquestionably arrhythmic. For these reasons, the study concentrated on hibernation. In addition, such an approach allowed the posing of questions about a specific physiological function rather than about pure mortality. Many factors, known and unknown interact to cause mortality, and a mere mortality study piques the curiosity about the actual causes of death. A few laboratory studies of circadian rhythms in hibernating golden-mantled squirrels in the laboratory have been published (Ruby et al., 1996, 1998). The results are not entirely comparable to the data of this paper, but the design of the other study differed because of a longterm protocol covering 2.5 years. These authors' results also suggested that the SCN pacemaker does not generate the euthermic bouts. Bouts persisted in lesioned animals but the periodicity was generally much accelerated and the bouts continued throughout the subjective summer provided in these purely laboratory studies (Ruby et al., 1998).

In the field data reported here, no fully lesioned animals were retrieved after arousal from winter hibernation, and only a small number of partially lesioned females, while $30 \%$ of intact control animals of both sexes were retrieved. The data imply that no fully lesioned animals survived the winter and that the hibernation bouts persisted but are not as regular as in intact animals. The SCN may play a vital role in energy expenditure regulation by helping ration out the limited body fat energy supply over the 6- to 8-month period of food lack in the high desert habitat of the Cascades. Lack of energy reserves is probably a very serious problem for adult males in the field; the early arousing mature males are photoperiodic and must be exposed to increasing day length for 8 weeks for stimulation of gonadal growth in order to reach a reproductive state before arousal of females from hibernation and their appearance above ground for breeding. Their habitat is snow covered, occasionally until May or even through June at high elevations. The aberrations seen in SCNlesioned animals are energy expensive. Even though these deviations from normal might increase energy expenditure by only a few percent, they could possibly be the difference between life and death.

Further research on SCN-lesioned wild rodent species in both field and laboratory is needed. Although such work is very labor intensive, results will undoubtedly illustrate many other important adaptive regulatory functions of the SCN as well as the specific selective environmental agents involved. Current information is extremely limited. 


\section{Acknowledgements}

The author wishes to thank Jill Krulas Walker, Dr. Daniel Holley, Gary Mele, and David Ledder for expert field assistance, as well as Jennifer Keller and Sierra Jones for computer assistance. Dr. Leon Hunter kindly arranged for use of The Desert Research Station, Barstow California. The staff of Mountain Lake Biological Station, Virginia, The High Desert Museum, Bend, Oregon and Wizard Falls Fish Hatchery, Camp Sherman, Oregon provided critically needed surgical space for the projects. The National Science Foundation supported the research under grants IBN-9603878 and IBN-9817096.

\section{References}

Alleva E, Fasolo A, Lipp H-P, Nadel L, Ricceri L (1995): Behavioral Brain Research in Naturalistic and Semi-Naturalistic Settings. London, Kluwer Academic.

Barnes B (1989): Freeze avoidance in a mammal: Body temperatures below $0^{\circ} \mathrm{C}$ in an Arctic hibernator. Science 44: 1593-1595.

Bowers MA (1995): Use of space and habitats by the eastern chipmunk (Tamias striatus). J Mamm 76: 12-21.

Aschoff J (1964): Survival value of diurnal rhythms. Symp Zool Soc London 13: 79-98.

Aschoff J, ed. (1981): Handbook of Behavioral Neurobiology 4: Biological Rhythms. New York, Plenum Press.

Dark J, Kilduff TS, Heller HC, Licht P, Zucker I (1990): Suprachiasmatic nuclei influence hibernation rhythms of golden-mantled ground squirrels. Brain Research 509: 111-118.

DeCoursey PJ, Krulas JR, Mele G, Holley DC (1997): Circadian performance of Suprachiasmatic nuclei (SCN)-lesioned antelope ground squirrels in a desert enclosure. Physiol Behav 62: 1099-1108.

DeCoursey PJ, Krulas JR (1998): Behavior of SCN-lesioned chipmunks in natural habitat: a pilot study. J Biol Rhythms 13: 229-244.

DeCoursey PJ, Walker JK, Smith SA (2000): A circadian pacemaker in free-living chipmunks: essential for survival? J Comp Physiol A 186: 169-180.

DeCoursey PJ (2001) Early research highlights at the Max-Planck Institute for Behavioral Physiology, Erling-Andechs and their influence on Chronobiology. In: Honma K, Honma S, eds., Zeitgebers, Entrainment and Masking of the Circadian System. Sapporo, Japan, University of Hokkaido Press, pp. 55-74.

DeCoursey PJ (2003a): The behavioral ecology and evolution of biological timing systems. In: Dunlap JC, Loros JL, DeCoursey PJ, eds., Chronobiology: Biological Timekeeping. Sunderland, MA, Sinauer Associates, Inc., pp. 26-65.

DeCoursey PJ (2003b): Functional organization of circadian systems in multicellular animals. In: Dunlap JC, Loros JL, DeCoursey PJ, eds., Chronobiology: Biological Timekeeping. Sunderland, MA, Sinauer Associates, Inc., pp. 144-178.

DeCoursey PJ (2003c): Cell physiology of circadian pacemaker systems in metazoan animals. In: Dunlap JC, Loros JL, DeCoursey PJ, eds., Chronobiology: Biological Timekeeping. Sunderland, MA, Sinauer Associates, Inc., pp. 180-210. 
Grahn DA, Miller JD, Houng VS, Heller HC (1994): Persistence of circadian rhythmicity in hibernating ground squirrels. Am J Physiol 26: R1251-R1258.

Hut RA, Barnes BM, Daan S (2002): Body temperature patterns before, during, and after semi-natural hibernation in the European ground squirrel. $J$ Comp Physiol B 172: $47-58$.

Karasov WH (1981): Daily energy expenditure and the cost of activity in a free-living mammal, the antelope ground squirrel. Oecologia 51: 253-259.

Klein DC, Moore RY, Reppert SM, eds. (1991): Suprachiasmatic Nucleus: the Mind's Clock. New York, Oxford University Press.

Körtner G, Geiser F (2000): The temporal organization of daily torpor and hibernation: circadian and circannual rhythms. Chronobiol Internat 17: 103-128.

Lyman CP, Willis JS, Malan A, Wang LCH, eds. (1982): Hibernation and Torpor in Mammals and Birds. New York, Academic Press.

Michener G (1992): Sexual differences in over-winter torpor patterns of Richardson's ground squirrels in natural hibernacula. Oecologia 89: 397-406.

Milsom WK, Osborne S, Chan PF, Hunter JD, Macleod JZ (1993): Sleep, hypothermia, and hibernation: metabolic rate and the control of breathing in golden-mantled ground squirrels. In: Carey C, Florant GL, Wunder BA, Horwitz B, eds., Life in the Cold: Ecological, Physiological, and Molecular Mechanisms. Boulder, Westview Press, pp. 233-240.

Moore RY, Leak RK (2001): Suprachiasmatic nucleus. In: Takahashi JS, Turek FW, Moore RY, eds., Handbook of Behavioral Neurobiology 12: Circadian Clocks. New York, Kluwer Academic/Plenum Publishers, pp. 141-179.

Pulawa LK, Florant GL (2000): The effects of caloric restriction on the body composition and hibernation of the golden-mantled ground squirrel (Spermophilus lateralis). Physiolog Biochem Zool 73: 538-546.

Ruby NF, Dark J, Heller HC, Zucker I (1996): Ablation of Suprachiasmatic nucleus alters timing of hibernation in ground squirrels. Proc Natl Acad Sci 93: 98649868.

Ruby NF, Dark J, Heller HC, Zucker I (1998): Suprachiasmatic nucleus: role in circannual body mass and hibernation rhythms of ground squirrels. Brain Res 782: 63-72.

Ruby NF (2003): Hibernation. When good clocks go cold. J Biolog Rhythms 18: 275-286.

Strijkstra AM (1999): Periodic euthermy during hibernation in the European ground squirrel: causes and consequences. $\mathrm{PhD}$ Thesis, University of Gröningen, The Netherlands.

Strijkstra AM, Hut RA, Millesi E, Daan S (1999): Energy expenditure during hibernation in European ground squirrels (Spermophilus citoles). In: Strijkstra AM, ed., Periodic euthermy during hibernation in the European ground squirrel: causes and consequences. PhD Thesis, University of Gröningen, The Netherlands.

Takahashi JS, Turek FW, Moore RY, eds. (2001): Handbook of Behavioral Neurobiology 12: Circadian Clocks. New York, Kluwer Academic/Plenum Publishers.

Trombulak SC (1987): Life history of the Cascade golden-mantled ground squirrel (Spermophilus saturatus). J Mamm 68: 544-554.

Vitaterna MH, King DP, Chang A-M, Kornhauser M, Lowrey PL et al. (1994): Mutagenesis and mapping of a mouse gene, Clock, essential for circadian behavior. Science 264: 719-725. 
Wassmer T, Wollnik F (1997): Timing of torpor bouts during hibernation in European hamster (Cricetus cricetus L.). J Comp Physiol B 167: 270-279.

Wolff JO (1996): Population fluctuations of mast-eating rodents are correlated with production of acorns. J Mamm 77: 850-856.

Wollnik F, Schmidt B (1995): Seasonal and daily rhythms of body temperature in the European hamster (Cricetus cricetus) under semi-natural condition. J Comp Physiol B 165: 171-182.

Wrazen JA, Wrazen LA (1982): Hoarding, body mass dynamics, and torpor as components of the survival strategy of the eastern chipmunk. J Mamm 63: 63-72.

Zimmer MB, Milsom WK (2001): Effects of changing ambient temperature on metabolic, heart, and ventilation rates during steady state hibernation in golden-mantled ground squirrels (Spermophilus lateralis). Physiolog Biochem Zool 74: 714-723.

Zucker I, Boshes M, Dark J (1983): Suprachiasmatic nuclei influence circannual and circadian rhythms of ground squirrels. Am J Physiol 244: R472-R480.

Zucker I, Ruby NF, Dark J (1993): The suprachiasmatic nucleus mediates rhythms of hibernation and daily torpor in rodents. In: Carey C, Florant GL, Wunder BA, Horwitz B, eds., Life in the Cold: Ecological, Physiological, and Molecular Mechanisms. Boulder, CO, Westview, pp. 277-289. 
Copyright of Biological Rhythm Research is the property of Swets \& Zeitlinger, BV and its content may not be copied or emailed to multiple sites or posted to a listserv without the copyright holder's express written permission. However, users may print, download, or email articles for individual use. 